\title{
Status of Vitamin D and its Association with Stroke Risk Factors in Patients with Acute Ischemic Stroke in a Tertiary Care Hospital
}

\author{
Lekhjung Thapa, ${ }^{1}$ Asis Shrestha, ${ }^{2}$ Manohar Pradhan, ${ }^{3}$ Tirtha Raj Bhandari, ${ }^{4}$ Shakti Shrestha, ${ }^{5}$ Ramesh Sharma \\ Poudel, ${ }^{\circ}$ Baburam Pokhrel, ${ }^{7}$ Raju Poudel ${ }^{8}$ \\ 'National Institute of Neurological and Allied Sciences, Bansbari, Kathmandu, Nepal, ${ }^{2}$ Kharanitar Primary Health Center, \\ Nuwakot, Nepal, ${ }^{3}$ College of Medical Sciences-Teaching Hospital, Chitwan, Nepal, ${ }^{4}$ Jutpani Primary Health Center, Chitwan, \\ ${ }^{5}$ Shree Medical and Technical College, Chitwan, Nepal, ${ }^{6}$ Chitwan Medical College Teaching Hospital, Chitwan, Nepal \\ ${ }^{7}$ Kathmandu University Medical College, Dhulikhel, Nepal, ${ }^{8} \mathrm{Grande}$ International Hospital, Dhapasi, Kathmandu, Nepal.
}

\section{ABSTRACT}

Introduction: Vitamin D deficiency has been associated with many neurological illnesses. The status of Vitamin D in Nepalese ischemic stroke patients is still unknown. This study aims to assess the status of vitamin D and its association with stroke risk factors in patients with acute ischemic stroke from Central Nepal.

Methods: A total of 60 patients with ischemic stroke were included in the study. Their clinical profile and Vitamin D status were assessed. Frequency distribution, Pearson $\chi^{2}$ test and Kruskal-Wallis test were performed for statistical analysis using SPSS-IBM 20.

Results: The median (IQR) age of the patient was $65(53.25,70.75)$ years, ranging from $18-87$ years. Thirty-four $(56.7 \%)$ were males. Fourty-eight $(80 \%)$ patients had hypertension and $34(56.7 \%)$ were smoker. Previous stroke was present in six (10\%) cases. Thirty-seven (61.6\%) patients had low levels of Vitamin D out of which $26(43.3 \%)$ had vitamin D insufficiency and $11(18.3 \%)$ had vitamin D deficiency. Vitamin D level was significantly associated with previous history of stroke $(\mathrm{P}=0.043)$.

Conclusions: Vitamin D deficiency occurs in patients with ischemic stroke. Previous episodes of stroke with low vitamin D levels could be a cause of recurrent strokes. Further studies are necessary to establish the role of vitamin D in acute ischemic stroke in Nepalese population.

Keywords: deficiency; nepal; stroke; vitamin D.

\section{INTRODUCTION}

Vitamin D has roles in immunity, cardiovascular and cerebrovascular physiology ${ }^{1}$ and its deficiency might be involved in the development of several diseases, including arterial hypertension, diabetes mellitus, heart failure, ${ }^{2}$ acute myocardial infarction ${ }^{3}$ and stroke. ${ }^{4}$ Its antitumor property has been studied in breast, ${ }^{5}$ prostate $^{6}$ and colon cancers. ${ }^{7}$ The overall health importance of vitamin $D$ is further supported by a meta-analysis that found a significant reduction of total mortality in patients who received vitamin D. ${ }^{8}$
Recent studies have linked low circulating level of vitamin $D$ with increased risk of cerebrovascular disease suggesting vitamin $D$ supplementation as a promising approach in the prevention of strokes. ${ }^{9-11}$ Besides this, status of vitamin D and its role in acute ischemic stroke patients is lacking in literature from Nepal. Baseline status of vitamin D may be useful in conducting the

Correspondence: Dr. Lekhiung Thapa, National Institute of Neurological and Allied Sciences, Bansbari, Kathmandu, Nepal. Email: drlekhjung@gmail.com, Phone: +977-9855060509. 
research on the role of supplementary vitamin $D$ in acute ischemic stroke patients. Therefore, this study was conducted to assess the status of vitamin D and its association with stroke risk factors in patients with acute ischemic stroke from Central Nepal.

\section{METHODS}

This was a cross sectional study conducted from Jan 2013 to May 2013 in patients admitted to the Neurology Department of College of Medical Sciences-Teaching Hospital with the diagnosis of ischemic stroke. An informed consent was obtained from all the patients and those refusing to investigate their vitamin $D$ levels were excluded from the study. Demographic profile, blood pressure, risk factors of stroke and vitamin D level were recorded.

Hypertension was defined as systolic blood pressure $\geq$ $140 \mathrm{~mm} \mathrm{Hg}$, diastolic blood pressure $\geq 90 \mathrm{~mm} \mathrm{Hg}$, or use of antihypertensive therapy..$^{12}$ Diabetes mellitus was diagnosed when fasting plasma glucose $\geq 126 \mathrm{mg} /$ dl or two hr post-prandial plasma glucose $\geq 200 \mathrm{mg} /$ $\mathrm{dl}$ or random plasma glucose $\geq 200 \mathrm{mg} / \mathrm{dl}$ or HBA $1 \mathrm{c} \geq$ $6.5 \%$ or patient already diagnosed and on treatment, based on American Diabetes Association Guidelines. ${ }^{13}$ Dyslipidemia was defined as total cholesterol $\geq 240$ $\mathrm{mg} / \mathrm{dl}$ or LDL $\geq 160 \mathrm{mg} / \mathrm{dl}$, or patient on lipid lowering drugs. ${ }^{14}$ Vitamin $D$ levels $\geq 30 \mathrm{ng} / \mathrm{ml}$ was taken as normal in our study. Low vitamin D levels $(<30 \mathrm{ng} /$ $\mathrm{ml})$ were classified into insufficiency $(20-29 \mathrm{ng} / \mathrm{ml})$ and deficiency $(<20 \mathrm{ng} / \mathrm{ml})$ states. ${ }^{2,15}$

The association between risk factors and vitamin-D level was determined using Pearson $\square^{2}$ test whereas the association between the continuous variables and vitamin-D level was determined using Kruskal-Wallis test. All the analysis was done using SPSS-IBM-20 and
$\mathrm{P}<0.05$ was taken as significant.

\section{RESULTS}

A total of 60 patients were included in this study. The median (IQR) age of the patient was $65(53.25,70.75)$ years, ranging from 18 to 87 years. The median (IQR) systolic and diastolic blood pressure were 150 (122.5, 170) $\mathrm{mmHg}$ and $90(70,100) \mathrm{mmHg}$ respectively. Thirty four (56.7\%) were male. Fourty eight $(80 \%)$ had hypertension. Thirty four $(56.7 \%)$ were smokers and $21(35 \%)$ patients were alcohol consumer. Previous history of stroke was present in six $(10 \%)$ cases. Out of 60 patients, $37(61.6 \%)$ had vitamin D levels lower than the normal value [26 (43.3\%) had vitamin D insufficiency and $11(18.3 \%)$ had vitamin D deficiency] (Table 1).

\begin{tabular}{|lll|}
\hline \multicolumn{2}{|l|}{ Table 1. Baseline characteristics. } \\
\hline $\begin{array}{l}\text { Baseline } \\
\text { characteristics }\end{array}$ & Category & $\mathbf{n}(\%)$ \\
(N=60) & & \\
Gender (Male) & Male & $34(56.7)$ \\
Hypertension & Yes & $48(80)$ \\
Diabetes & Yes & $12(20)$ \\
Dyslipidemia & Yes & $5(8.3)$ \\
Smoking & Yes & $34(56.7)$ \\
Alcohol intake & Yes & $21(35.0)$ \\
Rheumatic Heart & Yes & $3(5)$ \\
disease & Yes & $4(6.7)$ \\
Atrial fibrillation & Yes & $2(3.3)$ \\
Cardiomyopathy & Yes & $6(10)$ \\
Previous stroke & Normal $(\geq 30 \mathrm{ng} /$ & $23(38.3)$ \\
& $\mathrm{ml})$ & \\
& Insufficient $(20-29$ & $26(43.3)$ \\
Vitamin-D level & $\mathrm{ng} / \mathrm{ml})$ & $11(18.3)$ \\
& Deficient $(<20 \mathrm{ng} /$ & \\
& $\mathrm{ml})$ & \\
\hline
\end{tabular}

\begin{tabular}{|c|c|c|c|c|}
\hline \multirow{2}{*}{ Variables } & \multicolumn{3}{|l|}{ Vit-D level } & \multirow{2}{*}{ P- xvalue } \\
\hline & Normal $\mathrm{n}(\%)$ & Insufficient $\mathrm{n}(\%)$ & Deficient $n(\%)$ & \\
\hline Gender (Male) $(N=34)$ & $17(73.9)$ & $13(50.0)$ & $4(36.4)$ & 0.078 \\
\hline${ }^{+}$Age $(N=60)$ & 65.5 & 63 & 66 & 0.584 \\
\hline${ }^{+} \mathrm{SBP}(\mathrm{N}=60)$ & 160 & 140 & 140 & 0.618 \\
\hline${ }^{+} \mathrm{DBP}(\mathrm{N}=60)$ & 100 & 90 & 80 & 0.179 \\
\hline Hypertension $(\mathrm{N}=48$ ) & $18(78.3)$ & $21(80.8)$ & $9(81.8)$ & 0.963 \\
\hline Diabetes $(N=12)$ & $3(13.0)$ & $5(19.2)$ & $4(36.4)$ & 0.280 \\
\hline Dyslipidemia $(N=5)$ & 0 & $3(11.5)$ & $2(18.2)$ & 0.147 \\
\hline Smoking $(N=34)$ & $12(52.2)$ & $17(65.4)$ & $5(45.5)$ & 0.457 \\
\hline Alcohol $(\mathrm{N}=21)$ & $9(39.1)$ & $10(38.5)$ & $2(18.2)$ & 0.432 \\
\hline Rhematic Heart Disease $(\mathrm{N}=3)$ & $1(4.3)$ & $1(3.8)$ & $1(9.1)$ & 0.786 \\
\hline Atrial fibrillation $(\mathrm{N}=4)$ & 0 & $2(7.7)$ & $2(18.2)$ & 0.133 \\
\hline Cardiomyopathy $(\mathrm{N}=2)$ & $1(4.3)$ & 0 & $1(9.1)$ & 0.350 \\
\hline Previous stroke $(\mathrm{N}=6)$ & 0 & $3(11.5)$ & $3(27.3)$ & $0.043 *$ \\
\hline
\end{tabular}

${ }^{+}$median, ${ }^{*}$ statistically significant at $\mathrm{P}<0.05$ 
The one sample chi-square test for vitamin $D$ level showed that there is statistically significant differences in the various categories of vitamin $D$ level with previous history of stroke $(P=0.043)$. There were six patients who had a previous history of stroke and none of these patients had a normal level of vitamin D, instead $50 \%$ of these patients had insufficient vitamin $D$ level and remaining $50 \%$ had deficient level (Table 2 ).

\section{DISCUSSION}

The association of gender with vitamin $D$ level showed that more females $(5 \%)$ had lower vitamin D levels as compared to males though males in our study were higher $(13.4 \%)$ than the females. Though this relationship is not statistically significant $(P=0.078)$ this might suggest that taking vitamin $D$ deficient state into consideration, females are at more risk of having stroke than males.

Most of our patients were elderly (median age 65yrs) and there was no significant difference in the median age of patients at various levels of vitamin D. Low levels of 25-OH-vitamin D are present in at least half of the elderly population. ${ }^{2,10,16}$ Also, this age group is more prone to cerebrovascular diseases such as stroke. ${ }^{17}$ Studies have been done to find out whether the vitamin $D$ deficiency observed in elderly is associated to stroke. A study done by Poole et al observed reduced vitamin D levels $(77 \%)$ in acute stroke showing vitamin D deficiency as a potential risk marker for stroke. ${ }^{4}$ Low vitamin D levels were seen in $61.6 \%$ of our ischemic stroke patients $118.3 \%$ in deficiency and $43.3 \%$ in insufficiency levels). A study done by Pilz et al have showed that low levels of 25(OH)D and 1,25(OH)2 $D$ were independently predictive of fatal stroke, thus explaining vitamin D supplementation as a promising approach in prevention of stroke. ${ }^{10}$ Stepwise decrease in 25-OH-D levels were associated with stepwise increase in risk of symptomatic ischemic stroke in a large population-based prospective study. ${ }^{18}$

Several theories and mechanisms have been explained to describe how vitamin D deficiency can lead to stroke. Vitamin D receptors have a broad tissue distribution including vascular smooth muscle ${ }^{19}$ and endothelium. ${ }^{20}$ Furthermore, vitamin D deficiency influences vascular remodeling through modulation of smooth muscle cell proliferation, ${ }^{21}$ inflammation ${ }^{22}$ and thrombosis. ${ }^{23}$ Also, vitamin D deficiency leads to secondary hyperparathyroidism, and the increase in parathyroid hormone promotes myocyte hypertrophy ${ }^{24}$ and vascular remodeling. ${ }^{25}$ Parathyroid hormone related protein (PTHrP) acts as a proinflammatory cytokine and may contribute to the instability of the atherosclerotic plaques. ${ }^{26}$ These vascular changes are eventually responsible to cause stroke.

Deficiency of vitamin $D$ has been associated with hypertension, ${ }^{27}$ diabetes mellitus,28 and hyperlipidemia, ${ }^{29}$ which are the known risk factors for stroke. ${ }^{30}$ In our study, most of the patients who had risk factors for stroke such as hypertension, diabetes mellitus, dyslipidemia, smoking, alcohol intake, atrial fibrillation and previous history of stroke had low levels of vitamin D, suggesting role of vitamin $D$ in these risk factors leading to stroke.

Vitamin D deficiency is associated with increase in renin expression and angiotensin II production, leading to hypertension. ${ }^{31}$ In a prospective cohort study, plasma 25-OH-D has been inversely associated with risk of incident hypertension. ${ }^{27}$ Hypertension was the most common $(48,80 \%)$ modifiable risk factor in our study, and $62.5 \%$ of those hypertensives had low vitamin D levels suggesting clinical significance. However, there was no statistically significant association between hypertension and vitamin D level.

All the patients with previous history of stroke had either insufficient $(20-29 \mathrm{ng} / \mathrm{ml})$ or deficient $(<20 \mathrm{ng} /$ $\mathrm{ml}$ ) vitamin D levels, suggesting vitamin D insufficiency or deficiency as a risk factor for recurrent stroke. On the other hand, stroke patients are elderly with some neurological deficit or bed-bound, with poor exposure to sunlight and low dietary intake, which predispose them to suffer from vitamin D deficiency and its further consequences, stroke probably being one of them. ${ }^{32}$ This necessitates follow up of these patients, and monitoring of any vascular events in the future correlating with their changing vitamin D status. The statistically significant relationship of previous history of stroke with vitamin D level along with its clinical relevance suggests that vitamin $D$ supplement might be essential for patients who had first ever stroke to prevent recurrent stroke.

Despite of their proved and possible clinical significance, as none of the modifiable and non-modifiable risk factors except previous history of stroke showed statistically significant relationship with vitamin D level in our study, further study in larger population is suggestive.

\section{CONCLUSIONS}

Majority of stroke patients have low level of vitamin D. Previous episodes of stroke with low vitamin D levels could be a good predictor of recurrent strokes. Linking vitamin $D$ deficiency with increased strokes suggests role of vitamin D supplementation as a promising strategy to prevent strokes. But there are no enough studies to advocate vitamin D supplementation to prevent strokes in high risk individuals; or to prevent recurrent strokes 
in patients with past history of such vascular events. Further studies are recommended to show indirect or direct causal relationship between vitamin $D$ deficiency and stroke, and vitamin D supplementation in preventing strokes and its recurrences.

\section{ACKNOWLEDGEMENTS}

We thank Ms. Shova Sapkota, Ms. Dipa and Ms. Kalpana Pokhrel and all the staffs of CMS-TH who helped us in this study.

\section{REFERENCES}

1. Hewison M. An update on vitamin D and human immunity. Clin Endocrinol (Oxf). 2012;76(3):315-25.

2. Holick MF. Vitamin $D$ deficiency. $N$ Engl J Med. 2007;357(3):266-81.

3. Scragg R, Jackson R, Holdaway IM, Lim T, Beaglehole R. Myocardial infarction is inversely associated with plasma 25-hydroxyvitamin D3 levels: a community-based study. Int J Epidemiol. 1990;19(3):559-63.

4. Poole KE, Loveridge N, Barker PJ, Halsall DJ, Rose C, Reeve J, et al. Reduced vitamin D in acute stroke. Stroke. 2006;37(1):243-5.

5. Garland CF, Gorham ED, Mohr SB, Grant WB, Giovannucci EL, Lipkin $M$, et al. Vitamin D and prevention of breast cancer: pooled analysis. J Steroid Biochem Mol Biol. 2007;103(3-5):708-11.

6. Jacobs ET, Giuliano AR, Martinez ME, Hollis BW, Reid ME, Marshall JR. Plasma levels of 25-hydroxyvitamin D, 1,25-dihydroxyvitamin $\mathrm{D}$ and the risk of prostate cancer. J Steroid Biochem Mol Biol. 2004;89-90(1-5):533-7.

7. Murillo G, Matusiak D, Benya RV, Mehta RG. Chemopreventive efficacy of 25-hydroxyvitamin D3 in colon cancer. J Steroid Biochem Mol Biol. 2007;103(3-5):763-7.

8. Autier P, Gandini S. Vitamin D supplementation and total mortality: a meta-analysis of randomized controlled trials. Arch Intern Med. 2007;167(16):1730-7.

9. Chowdhury R, Stevens S, Ward H, Chowdhury S, Sajjad A, Franco $\mathrm{OH}$. Circulating vitamin $\mathrm{D}$, calcium and risk of cerebrovascular disease: a systematic review and meta-analysis. Eur J Epidemiol. 2012;27(8):581-91.

10. Pilz S, Dobnig H, Fischer JE, Wellnitz B, Seelhorst U, Boehm $\mathrm{BO}$, et al. Low vitamin d levels predict stroke in patients referred to coronary angiography. Stroke. 2008;39(9):2611-3.

11. Buell JS, Dawson-Hughes B, Scott TM, Weiner DE, Dallal GE, Qui WQ, et al. 25-Hydroxyvitamin D, dementia, and cerebrovascular pathology in elders receiving home services. Neurology. 2010;74(1):18-26.

12. The Seventh Report of the Joint National Committee on Prevention, Detection, Evaluation, and Treatment of High Blood Pressure. Available at http://www.nhlbi.nih.gov/ files/docs/guidelines/jnc7full.pdf. (accessed 10 Jan 2013)

13. American Diabetes Association. Diagnosis and Classification of Diabetes Mellitus. Diabetes Care. 2010;33(Suppl 1):S62S69.

14. Jellinger PS, Smith DA, Mehta AE, Ganda O, Handelsman
Y, Rodbard HW, et al. American Association of Clinical Endocrinologists' guidelines for management of dyslipidemia and prevention of atherosclerosis. Endocr Pract. 2012;18(Suppl 1):1-78.

15. Diaz VA, Mainous AG, 3rd, Carek PJ, Wessell AM, Everett CJ. The association of vitamin D deficiency and insufficiency with diabetic nephropathy: implications for health disparities. J Am Board Fam Med. 2009;22(5):521-7.

16. Eriksen EF, Glerup H. Vitamin D deficiency and aging: implications for general health and osteoporosis. Biogerontology. 2002;3(1-2):73-7.

17. Shuaib A, Hachinski VC. Mechanisms and management of stroke in the elderly. CMAJ. 1991;145(5):433-43.

18. Brondum-Jacobsen P, Nordestgaard BG, Schnohr P, Benn M. 25-hydroxyvitamin $\mathrm{D}$ and symptomatic ischemic stroke: an original study and meta-analysis. Ann Neurol. 2013;73(1):38-47.

19. Merke J, Hofmann W, Goldschmidt D, Ritz E. Demonstration of 1,25(OH)2 vitamin D3 receptors and actions in vascular smooth muscle cells in vitro. Calcif Tissue Int. 1987;41(2):112-4.

20. Merke J, Milde P, Lewicka S, Hugel U, Klaus G, Mangelsdorf DJ, et al. Identification and regulation of 1,25-dihydroxyvitamin D3 receptor activity and biosynthesis of 1,25-dihydroxyvitamin D3. Studies in cultured bovine aortic endothelial cells and human dermal capillaries. J Clin Invest. 1989;83(6):1903-15.

21. Mitsuhashi T, Morris RC, Jr., Ives HE. 1,25-dihydroxyvitamin D3 modulates growth of vascular smooth muscle cells. J Clin Invest. 1991;87(6):1889-95.

22. Rigby WF, Denome S, Fanger MW. Regulation of lymphokine production and human $\mathrm{T}$ lymphocyte activation by 1,25-dihydroxyvitamin D3. Specific inhibition at the level of messenger RNA. J Clin Invest. 1987;79(6):1659-64.

23. Aihara K, Azuma H, Akaike M, Ikeda Y, Yamashita M, Sudo T, et al. Disruption of nuclear vitamin D receptor gene causes enhanced thrombogenicity in mice. J Biol Chem. 2004;279(34):35798-802.

24. Schluter KD, Piper HM. Trophic effects of catecholamines and parathyroid hormone on adult ventricular cardiomyocytes. Am J Physiol. 1992;263(6 Pt 2):H1739-46.

25. Perkovic V, Hewitson TD, Kelynack KJ, Martic M, Tait MG, Becker GJ. Parathyroid hormone has a prosclerotic effect on vascular smooth muscle cells. Kidney Blood Press Res. 2003;26(1):27-33. 
Thapa et al. Status of Vitamin D and its Association with Stroke Risk Factors in Patients with Acute Ischemic Stroke in a Tertiary ...

26. 26. Martin-Ventura JL, Ortego M, Esbrit P, Hernandez-Presa MA, Ortega L, Egido J. Possible role of parathyroid hormone-related protein as a proinflammatory cytokine in atherosclerosis. Stroke. 2003;34(7):1783-9.

27. 27. Forman JP, Giovannucci E, Holmes MD, Bischoff-Ferrari HA, TworogerSS, WillettWC, etal.Plasma25-hydroxyvitamin $\mathrm{D}$ levels and risk of incident hypertension. Hypertension. 2007;49(5):1063-9.

28. 28. Afzal S, Bojesen SE, Nordestgaard BG. Low 25-hydroxyvitamin $\mathrm{D}$ and risk of type 2 diabetes: a prospective cohort study and metaanalysis. Clin Chem. 2013;59(2):381-91.

29. 29. Anderson JL, May HT, Horne BD, Bair TL, Hall NL, Carlquist JF, et al. Relation of vitamin D deficiency to cardiovascular risk factors, disease status, and incident events in a general healthcare population. Am J Cardiol. 2010;106(7):963-8.

30. 30. Boysen G, Nyboe J, Appleyard M, Sorensen PS, Boas J, Somnier F, et al. Stroke incidence and risk factors for stroke in Copenhagen, Denmark. Stroke. 1988;19(11):1345-53.

31. 31. Li YC, Kong J, Wei M, Chen ZF, Liu SQ, Cao LP. 1,25-Dihydroxyvitamin $\mathrm{D}(3)$ is a negative endocrine regulator of the renin-angiotensin system. J Clin Invest. 2002;110(2):229-38.

32. 32. Poole KE, Reeve J, Warburton EA. Falls, fractures, and osteoporosis after stroke: time to think about protection? Stroke. 2002 May;33(5):1432-6. 